Sharif University of Technology
Scientia Iranica
SCIENTIA
I RAN ICA
http://scientiairanica.sharif.edu

\title{
Investigation of bridge abutment displacements constructed on piles and geogrid reinforced soil using the finite-element method
}

\author{
H. Taherkhani ${ }^{\mathrm{a}, *}$, M. Tajdini ${ }^{\mathrm{b}}$, A. Rezaee Arjroodic ${ }^{\mathrm{c}}$, and H. Zartaj ${ }^{\mathrm{b}}$ \\ a. Department of Civil Engineering, University of Zanjan, Zanjan, Iran. \\ b. Department of Civil Engineering, Tabriz University, Tabriz, East Azarbaijan Province, Iran. \\ c. Road, Housing \& Urban Development Research Center, Tehran, Iran.
}

Received 31 May 2016; received in revised form 4 March 2017; accepted 11 November 2017

\author{
KEYWORDS \\ Abutment; \\ Pile; \\ Geogrid; \\ Displacement; \\ FEM.
}

\begin{abstract}
One of the major problems of highway and railway bridges is the settlement of the bridge abutments, whose reduction has always been set as the research target. Two methods that have been widely used for controlling the settlement are either reinforcing the abutment subsoil with geogrid or constructing the abutments on piles. This paper describes the application of a two-dimensional Finite-Element Method (FEM) by using Plaxis 2D V8.5 for comparing the performances of these two methods. The effect of the geogrid normal stiffness, length, and depth of reinforcement on the horizontal and vertical displacements of abutment is also investigated. Data from an instrumented bridge abutment have been used for the model verification. The reduction of the bridge abutment, the vertical settlement, and the horizontal displacement by pile and geogrid have been analysed and compared. It is found that constructing the abutment on piles has a better performance in reducing the vertical settlement of the bridge abutment. However, lower lateral displacement can be obtained by using a geogrid with higher normal stiffness. It is also found that while the vertical settlement is not affected by the geogrid stiffness, the horizontal displacement of the abutment decreases by increasing the stiffness.
\end{abstract}

(C) 2019 Sharif University of Technology. All rights reserved.

\section{Introduction}

One of the geotechnical problems of highway construction is encountering soft soils in pavement subgrade and foundation of bridge abutments [1]. The soft soils can easily cause settlement of bridge and pavement, resulting in uneven surface on the roadway. To overcome this problem, a variety of approaches have been proposed by the engineers worldwide, whereas the

*. Corresponding author. Tel.: +982433054206

E-mail addresses: Taherkhani.hasan@znu.ac.ir (H.

Taherkhani); m.tajdini@tabrizu.ac.ir (M. Tajdini);

Rezaeear@yahoo.com (A. Rezaee Arjroodi);

H.zartaj@tabrizu.ac.ir (H. Zartaj)

doi: $10.24200 /$ sci. 2017.4591 optimum solution is subjective. For a long time, piles have been used to transfer the bridge abutment loads to the competent soil in depth or taking that by the friction between the piles' surface and the surrounding soil [2]. Another method for controlling the settlement of abutment on soft soil is reinforcing the sub soil by geosynthetics [3]. A number of studies have been carried out to investigate each method, some of which are presented relevant to our study in the following.

Hara et al. [4] conducted two field tests on bridge abutment constructed on weak soil and investigated the pile behaviour by monitoring the responses and using them for verification of the numerical modelling by finite-element method. According to their results, Biot's theory could well predict the pile displacements; thus, they suggested using this theory in modelling. 
Lee and $\mathrm{Wu}[5]$ used geosynthetics and their combination with preloading for reinforcing bridge abutments in 4 different projects and studied their behaviour by monitoring the responses. They found that the lateral displacements and settlement were significantly reduced by geogrid reinforcement and preloading, such that the horizontal strains under a load level of $80 \mathrm{kPa}$ were about $0.2 \%$.

Skinner and Rowe [6] studied a bridge abutment (6 $\mathrm{m}$ long) reinforced by geosynthetics. They found that the increase of length and stiffness of underlying layers was more significant than that of the overall bearing capacity on the stability of bridge.

Ellis and Springman [7] investigated the interaction of soil and a bridge abutment constructed on clay soil and found its 2D plane strain model to determine load-displacement using the non-linear method. The model was also placed in centrifuge and came to a result that the plain strain model could well predict the loaddisplacement behaviour.

Wang et al. [8] investigated the behaviour of bridge abutments on soft soil using finite-element modelling in ABAQUS. Considering plane strain in finite-element modelling, the behaviour of embankment and abutment was well predicted. Cam-clay model was used to simulate the behaviour of clay soil. They found that the cam-clay model could well predict the consolidation behaviour of saturated clay in interaction of soil-structures.

Fahel et al. [9] investigated the behaviour of geogrid reinforced soil and its interaction with bridge abutment in highway SC-101 in Brazil. Their results showed that reinforcement of soil resulted in the decrease of lateral displacement of bridge abutment, and it was more effective than the traditional methods were, such as berm.

Zheng and Fox [10] investigated the performance of bridge abutments reinforced by geogrid using discrete element method, and found that the results obtained by discrete elements method for vertical and horizontal displacements and the tensile stresses and the corresponding strains were consistent with those measured in the field. They also found that the soil compaction, the distance between anchors, and the loads on bridge had the highest effect on the lateral displacements and settlement of bridge abutment. As observed, their performance in the same conditions for reducing the displacement has not been compared yet, where their comparison is the novelty of this research.

With the objective of comparing the performances of pile and geogrid in reducing the vertical and lateral deformation of a bridge abutment settled on soft soil, a two-dimensional finite-element analysis was conducted using the Plaxis 2D V8.5. For verification of the model, the data obtained from monitoring the deformations in a real scale project were applied. Next, numerical modelling was carried out to perform the analysis and comparison of two cases of Piled bridge Abutment (PA) and Geogrid Reinforced Abutment (GRA). Furthermore, a parametric investigation was performed on the effects of the properties of the geogrid reinforcement, namely the length, depth of reinforcement, and normal stiffness, on the displacement of abutments.

\section{Real-scale abutment modelling}

2.1. Modelling the Piled bridge Abutment (PA) Figure 1 shows a section of the abutment used in this study. From top to bottom, the soil types include highly organic soil (Ap) with the thickness of $6.2 \mathrm{~m}$, Alluvial clay 1 (Ac1) with the thickness of $5.2 \mathrm{~m}$, volcanic ash (Av) with the thickness of $3.8 \mathrm{~m}$, Alluvial clay 2 (Ac2) with the thickness of $6.1 \mathrm{~m}$, and bedrock.

The abutment is designed with dimensions of $10 \mathrm{~m}$ in width, $10 \mathrm{~m}$ in length, and $9 \mathrm{~m}$ in height, which is supported by a group of $25(5 \times 5)$ piles. The piles are made of steel with circular cross-section with $800 \mathrm{~mm}$ in diameter, $12 \mathrm{~mm}$ in thickness, and $12 \mathrm{~m}$ in length. Therefore, Figure 1 illustrates the cross-section of the fill and the abutment perpendicular to the bridge axis (Figure 1(b)). To reduce the vertical and horizontal displacements of the ground due to the filling, a layer of sand with the thickness of $3 \mathrm{~m}$ has been constructed as pre-loading prior to the construction of the piles and abutment.

Figure 2 (a to h) shows the process of constructing the fill, as follows:

a) After constructing the sand drains, the sandmat was constructed up to the level of $1.3 \mathrm{~m}$ from the initial ground level and, then, laid out for 150 days;

b) For pre-loading, the fill with a height of $1.7 \mathrm{~m}$ was constructed with a rate of $10 \mathrm{~cm} /$ day on the sand mat and was laid out for 60 days. Therefore, the total height of the sand mat and the fill for preloading from the initial ground level is $3 \mathrm{~m}$;

c) A part of the pre-loading layer was removed to construct the abutment and the piles. Then, the fill behind the abutment was constructed again up to a height of $3 \mathrm{~m}$;

d) The filling continued to a height of $7.6 \mathrm{~m}$ with a rate of $4 \mathrm{~cm} /$ day and, then, left for 400 days;

e) Three meters of the upper part of the fill was removed and the rest was left for 150 days;

f) The fill was constructed up to a height of $8.5 \mathrm{~m}$ at a rate of $5 \mathrm{~cm}$ per day;

g) The deck load was applied on the abutment and was left for 200 days to be consolidated.

h) The constant loads were applied for 200 days in last stage construction. 


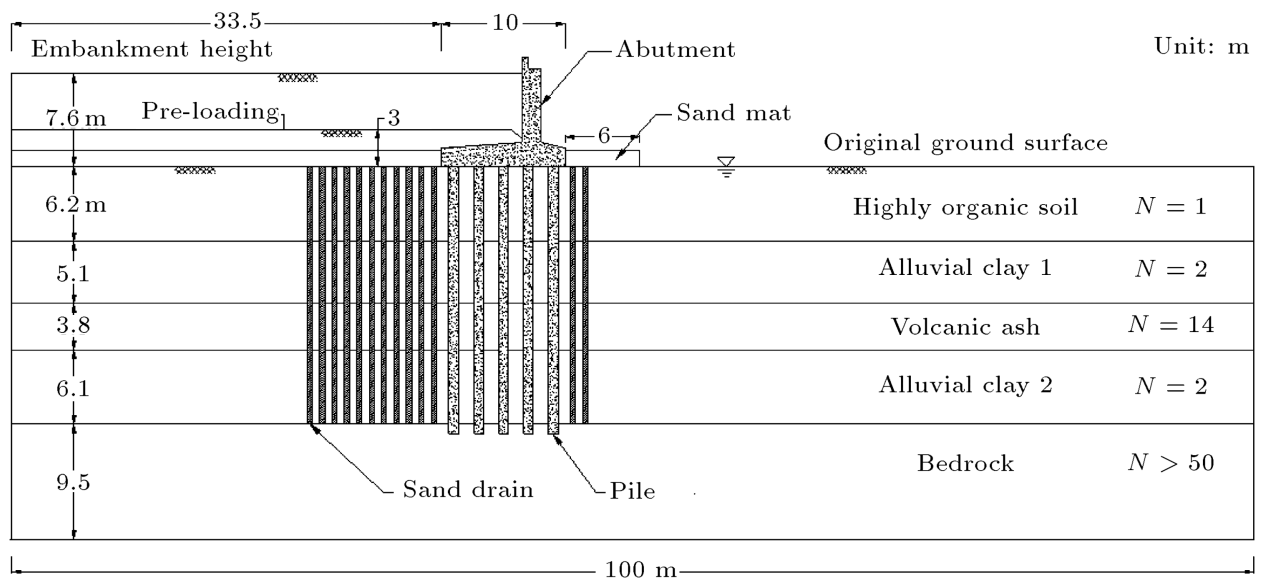

(a) Longitudinal section

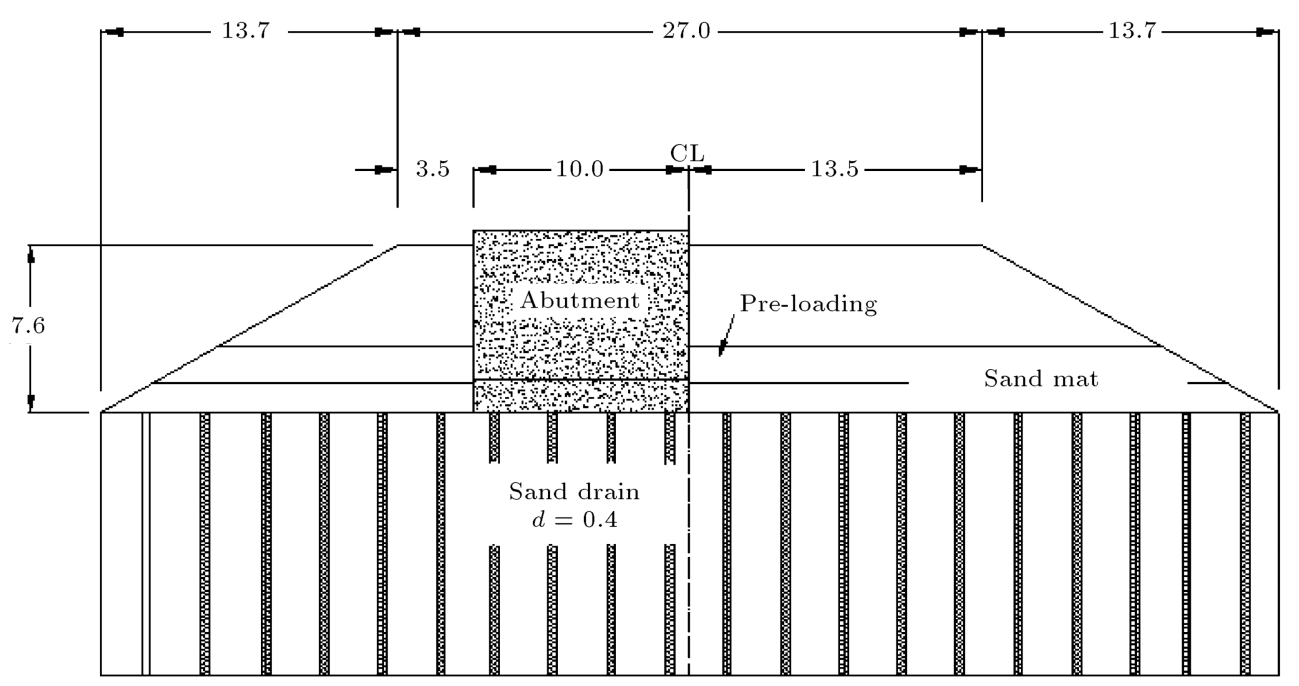

(b) Transverse section

Figure 1. Cross-section of abutment: (a) Longitudinal section and (b) transverse section.

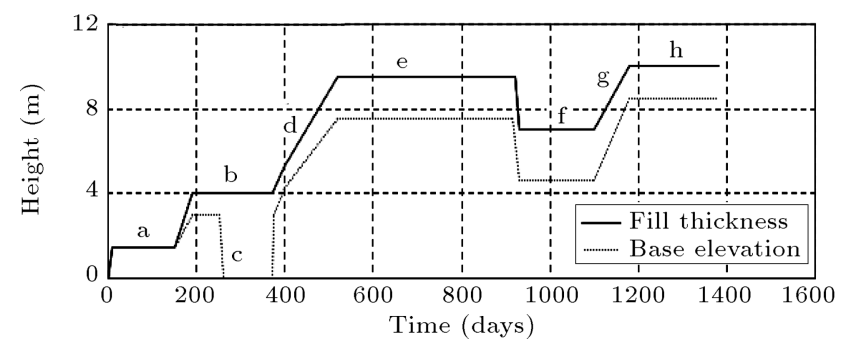

Figure 2. Process of constructing the filling.

In Figure 2, the solid line shows the thickness of the filled soil from the original ground level, and the grey line shows the height of fill from the ground level. Due to the settlement of the original ground during the construction process, the height of the filled soil is higher than that of the original level of the ground.

The fill soils were simulated using the MohrCoulomb model. The soil density was obtained from in situ density tests, $\gamma_{t 1}$, and was modified for the settlement during construction; in addition, the weight in $3 \mathrm{D}$ space was transferred to $2 \mathrm{D}$ one. The cohesion (c) and the internal friction of the soil $(\varphi)$ were obtained from CD-tests results. The abutment material was assumed linear and its properties, such as density, elastic modulus, and Poisson's ratio, were assumed as those for reinforced concrete. In $2 \mathrm{D}$ analysis, a row of piles was simplified as a wall of plane strain, as recommended by Randolph [2003]. The arrangement of the piles beneath the abutment is shown in Figure 3 . The plane strain wall was assumed linear in the analysis. The behaviors of clay and organic soils were simulated by modified Cam-clay model. Table 1 shows all of the materials properties and their configuration used in the analysis.

Considering the sand drains, instead of their circular cross-section, an equivalent rectangular section, perpendicular to the bridge axis, was used. Thus, the flow rate of the two sections should be equal, and Eq. (1) must be satisfied.

$$
T_{V 1}=T_{V 2}
$$


Table 1. Embankment and ground properties.

\begin{tabular}{|c|c|c|c|c|c|c|c|c|}
\hline \multicolumn{9}{|c|}{ Cam-clay materials (thickness of embankment is $7.6 \mathrm{~m}$ ) } \\
\hline Material & $\lambda$ & $\boldsymbol{K}$ & $e_{0}$ & \multicolumn{2}{|c|}{$p_{c}\left(\mathrm{kN} / \mathrm{m}^{2}\right)$} & $\gamma\left(\mathrm{kN} / \mathrm{m}^{3}\right)$ & $K_{0}$ & $k(\mathrm{~m} / \mathrm{s})$ \\
\hline Ap & 0.846 & 0.169 & 3.44 & \multicolumn{2}{|l|}{52} & 3 & 0.8 & $1 \mathrm{E}-10$ \\
\hline Ac1 & 0.260 & 0.052 & 1.51 & \multicolumn{2}{|l|}{135} & 6 & 0.5 & $1 \mathrm{E}-10$ \\
\hline Ac2 & 0.391 & 0.078 & 1.75 & \multicolumn{2}{|l|}{137} & 6 & 0.5 & $1 \mathrm{E}-10$ \\
\hline \multicolumn{9}{|c|}{ Mohr-coulomb materials } \\
\hline Material & \multicolumn{2}{|c|}{$E\left(\mathrm{kN} / \mathrm{m}^{2}\right)$} & $\vartheta$ & $\varphi\left({ }^{\circ}\right)$ & $\left(\mathbf{k N} / \mathbf{m}^{2}\right)$ & \multicolumn{2}{|c|}{$\gamma_{t}\left(\mathrm{kN} / \mathrm{m}^{\mathbf{3}}\right)$} & $k(\mathrm{~m} / \mathrm{s})$ \\
\hline Sand mat & \multicolumn{2}{|c|}{5000} & 0.30 & 30 & 0 & \multicolumn{2}{|c|}{18} & 1E-04 \\
\hline Av & \multicolumn{2}{|c|}{15000} & 0.30 & 30 & 50 & \multicolumn{2}{|c|}{16} & $1.7 \mathrm{E}-06$ \\
\hline \multicolumn{9}{|c|}{ Elastic materials } \\
\hline Material & \multicolumn{3}{|c|}{$E\left(\mathrm{kN} / \mathrm{m}^{2}\right)$} & $\vartheta$ & \multicolumn{2}{|c|}{$\gamma_{t}\left(\mathrm{kN} / \mathrm{m}^{3}\right)$} & \multicolumn{2}{|r|}{$k(\mathrm{~m} / \mathrm{s})$} \\
\hline Abutment & \multicolumn{3}{|c|}{$2.5 \mathrm{E}+07$} & 0.17 & \multicolumn{2}{|r|}{24.5} & \multicolumn{2}{|r|}{$1 \mathrm{E}-20$} \\
\hline Bed rock & \multicolumn{3}{|c|}{300000} & 0.30 & & 20 & \multicolumn{2}{|r|}{$1 \mathrm{E}-05$} \\
\hline \multicolumn{9}{|c|}{ Embankment } \\
\hline$H(\mathbf{m})$ & \multicolumn{3}{|c|}{$\gamma_{t}\left(\mathrm{kN} / \mathrm{m}^{3}\right)$} & $\left(\mathrm{kN} / \mathrm{m}^{2}\right)$ & $\vartheta$ & $\varphi\left({ }^{\circ}\right)$ & & $\left(\mathrm{kN} / \mathrm{m}^{2}\right)$ \\
\hline $0-4.0$ & & 23 & & 5000 & 0.30 & 16.5 & & 55 \\
\hline $4.0-6.1$ & & 1.5 & & 5000 & 0.30 & 16.5 & & 55 \\
\hline $6.1-7.6$ & & 9.5 & & 5000 & 0.30 & 16.5 & & 55 \\
\hline
\end{tabular}

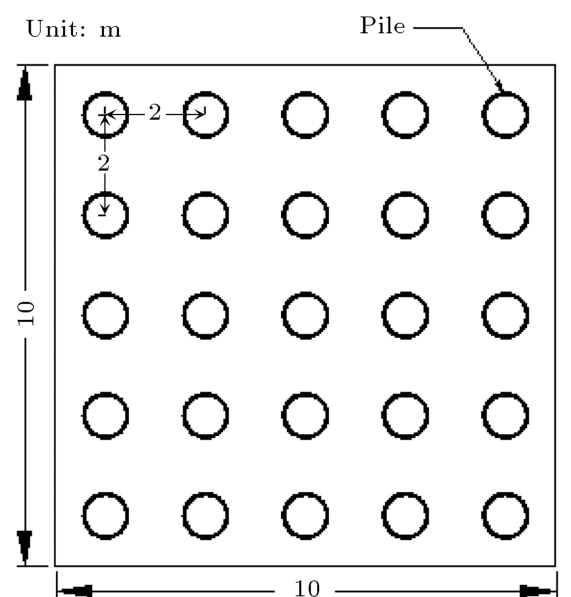

Figure 3. Arrangement of piles beneath the abutment.

where $T_{V}$ is time factor (in consolidation). The behavior of sand drains materials was simulated using Mohr-Coloumb model.

The loads applied on the abutment through bridge deck were calculated according to local loading code, for which the dead load, live load, and braking load were considered. Figure 4 shows the geometry of the abutment as well as the dead, live, and braking loads applied per unit length of the abutment.

\subsubsection{Analysis of the model}

15-noded triangular elements with 12 Guassian points were used for modelling. Plate elements were used for piles. Considering time-dependent dissipation of excess pore pressure, the analysis in all phases was performed

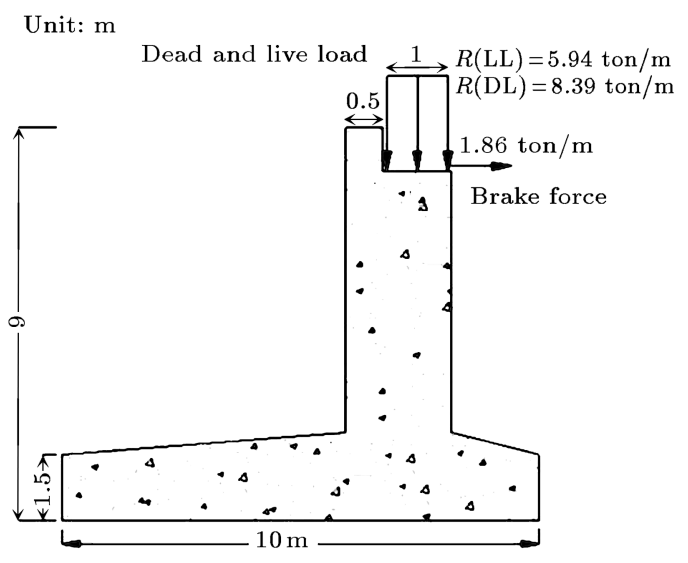

Figure 4. The geometry and applied loads on abutment.

using the consolidation analysis. Standard boundary conditions in Plaxis were considered in modelling, in which the left and right boundaries were constrained horizontally, and the boundary at the bottom of the model was constrained in both vertical and horizontal directions. The left and right boundaries are far enough to minimize the effect of the abutment displacements. After defining the geometry of the model and assigning properties to the materials, the meshing was designed, for which finer meshes were considered for the spaces between the piles and sand drains. Figure 5 shows the model together with the FE mesh. For the boundary at the bottom, constrained flow and consolidation were considered to prevent the water flow and allow for the establishment of the excess pore water pressure. For the left and right boundaries, constrained consolidation 


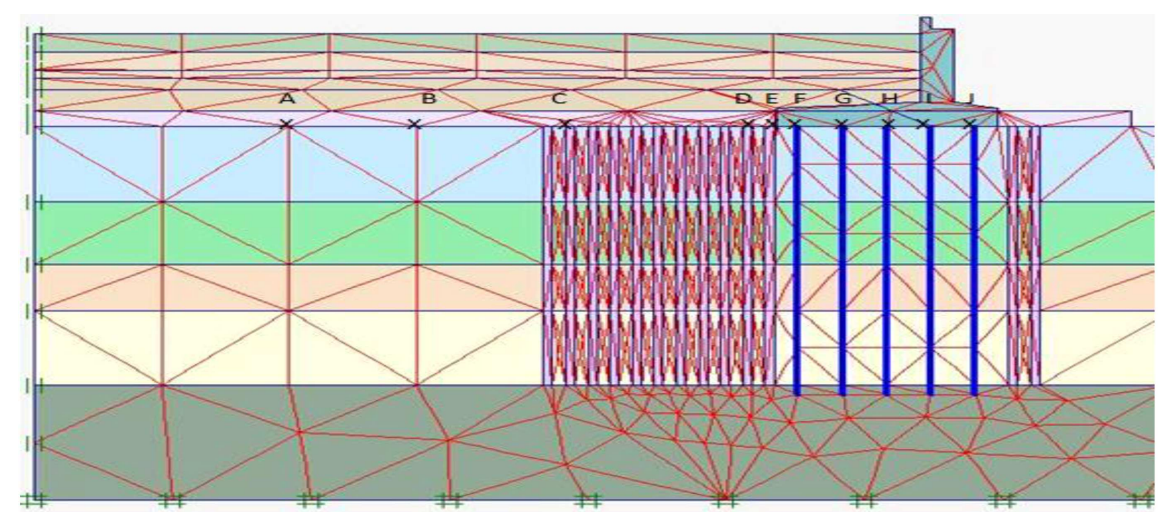

Figure 5. Schematic presentation of model for PA.

was considered as the conditions of pore water pressure during the consolidation. Computation of the constructed abutment on pile was done in 9 consolidation analysis phases, and the whole process of construction and consolidation lasted 1380 days. The analysis was conducted to determine the horizontal and vertical displacements of the model.

\subsection{Modelling the Geogrid Reinforced Abutment (GRA)}

The abutment constructed on the piles, as described in the previous sections, was analysed again with replacing the piles and the embankment with geogrid reinforced soil beneath and behind the abutment (Figure 6). The geometry of the GRA is the same as that of the PA, as described in the previous section. The process of constructing the abutment is also the same as that of the PA, except that, during filling the embankment soil, the geogrid layers are placed at $40 \mathrm{~cm}$ intervals, and 7 layers of geogrid have been used for reinforcing the soil beneath the abutment.

Soil with higher quality was used between the geogrids, for which the properties are presented in Table 2. The same behaviour and parameters, similar to the case of PA, were utilized for the case of GRA. In numerical analysis, the geogrid element was assumed elastic. The distance between the geogrid layers is $0.4 \mathrm{~m}$; their base normal stiffness is assumed $500 \mathrm{kN} / \mathrm{m}$; the depth of reinforced soil beneath the abutment is $3.2 \mathrm{~m}$. In order to investigate the effects of different properties of geogrid reinforcement on the vertical and horizontal displacements of abutment, different lengths, normal stiffness values, and depths of reinforced soil were investigated, as shown in Table 3 .

Table 2. Properties of the soil used between the geogrid layers.

\begin{tabular}{ccccccc}
\hline Materials & $\Phi\left({ }^{\circ}\right)$ & $\boldsymbol{C}\left(\mathrm{kN} / \mathbf{m}^{\mathbf{2}}\right)$ & $\boldsymbol{v}$ & $\boldsymbol{E}\left(\mathrm{kN} / \mathrm{m}^{\mathbf{2}}\right)$ & $\boldsymbol{\gamma}_{\text {unsat }}\left(\mathrm{kN} / \mathbf{m}^{\mathbf{3}}\right)$ & $\boldsymbol{\gamma}_{\text {unsat }}\left(\mathrm{kN} / \mathrm{m}^{\mathbf{3}}\right)$ \\
\hline Soil between the geogrids & 35 & 1 & 0.3 & 3000 & 19 & 21 \\
\hline
\end{tabular}

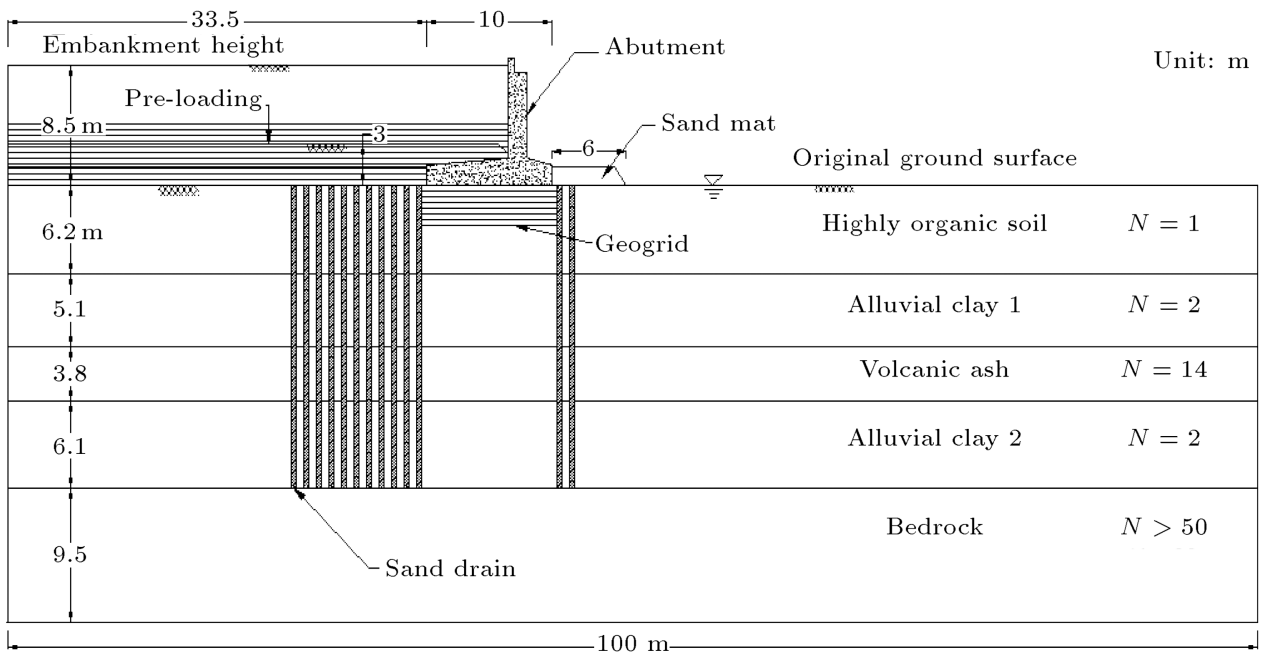

Figure 6. The geometry of GRA. 
Table 3. Evaluated properties of GRA.

\begin{tabular}{lcccc}
\hline \multicolumn{1}{c}{ Property } & \multicolumn{4}{c}{ Values } \\
\hline Length $(\mathrm{m})$ & 11 & 17 & 21 & 25 \\
Normal stiffness $(\mathrm{kN} / \mathrm{m})$ & 500 & 1000 & 1500 & - \\
Depth of reinforcement $(\mathrm{m})$ & 3.2 & 4.8 & 6.2 & 8 \\
\hline
\end{tabular}

15-noded triangular elements with 12 Guassian points were used in modelling the GRA. Geogrid element was employed for modelling the geogrids. The computation of Geogrid Reinforced Abutment (GRA) was conducted in 37 phases of consolidation analysis. The total time of construction process was 1380 days.

\section{Results of analysis}

\subsection{Piled bridge Abutment (PA)}

Figure $7(\mathrm{a})$ shows the history of the maximum settlement of ground from its initial level. As observed, the measured and calculated values are well consistent. Figure 7(b) shows the maximum horizontal displacement of the pile head on the inner side of bridge's abutment. As observed, there is slight discrepancy between the measured and calculated values, which is more noticeable after removing the 3-m upper part of the abutment. In addition, the maximum horizontal displacement under the abutment was calculated to be $12 \mathrm{~cm}$, while the measured value was $17 \mathrm{~cm}$. This discrepancy is attributed to the modelling assumptions, and that the 3-dimensional interaction mechanisms between the soil and piles have not been well simulated by the 2-dimensional modelling in this analysis. In

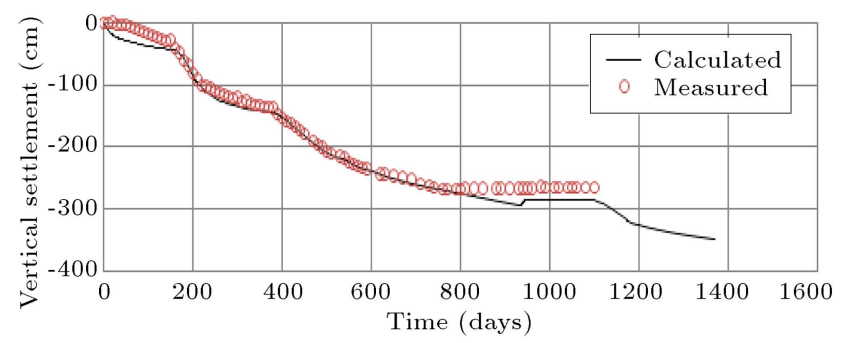

(a)

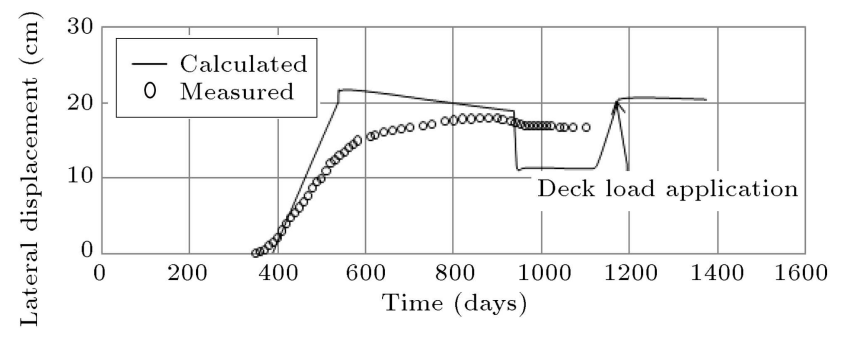

(b)

Figure 7. The comparison of measured and calculated values of $(a)$ the maximum vertical settlement and (b) the maximum lateral displacement of pile head.

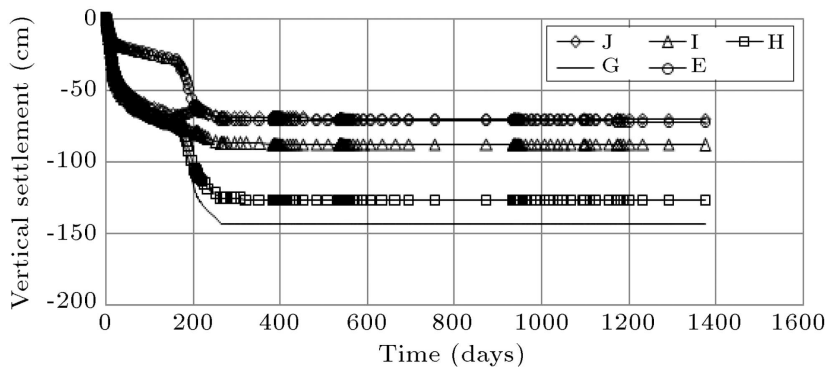

Figure 8. The history of vertical settlement of abutment at different points.

general, before removing the upper part, the horizontal displacement of the piles head, calculated by the model, is reliable and is not accurate after that.

Figure 8 shows the vertical settlement of points E, G, H, I, and J on the foot of abutment, as shown in Figure 5. As observed, point $\mathrm{G}$ has the highest vertical settlement before construction of piles. However, after construction of the piles, the settlement of the points stopped, indicating that the piles under the abutment prevented the settlement of the abutment.

\subsection{Geogrid Reinforced Abutment (GRA)}

In order to investigate the effect of geogrid length on the vertical and horizontal displacements of abutment, different lengths of $11,17,21$, and $25 \mathrm{~m}$, all with the normal stiffness of $500 \mathrm{kN} / \mathrm{m}$ and depth of reinforcement of $3.2 \mathrm{~m}$, were used in the modelling. Figures 9 and 10 show the history of the vertical and

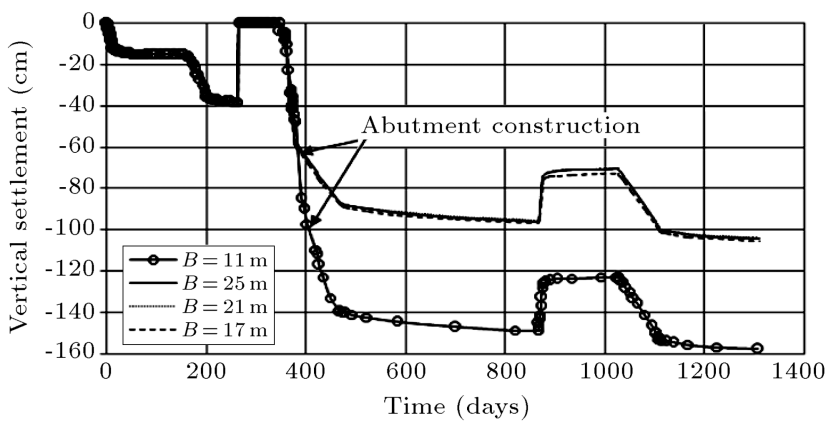

Figure 9. The vertical settlement of abutment for different lengths of geogrid.

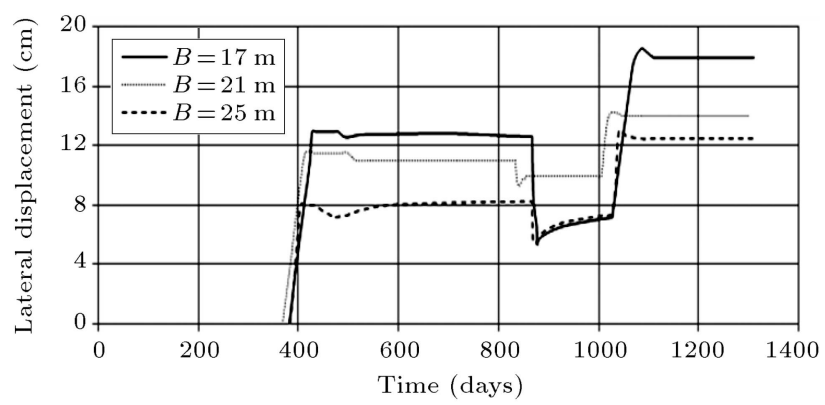

Figure 10. The horizontal displacement of abutment for different lengths of geogrid. 


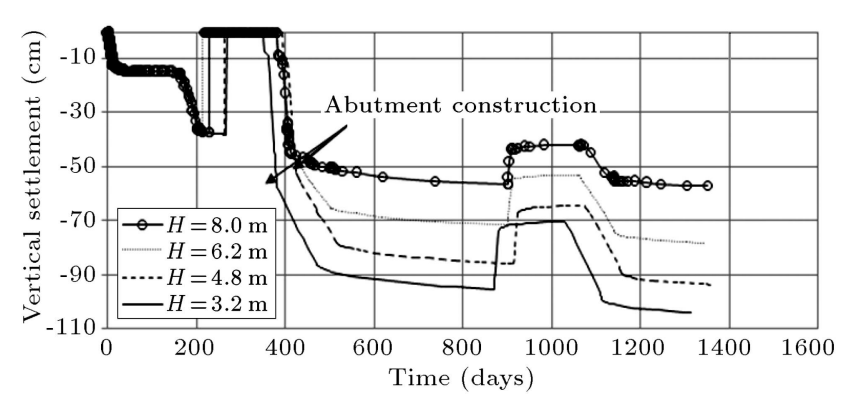

Figure 11. The maximum vertical settlement of abutment for different depths of reinforcement.

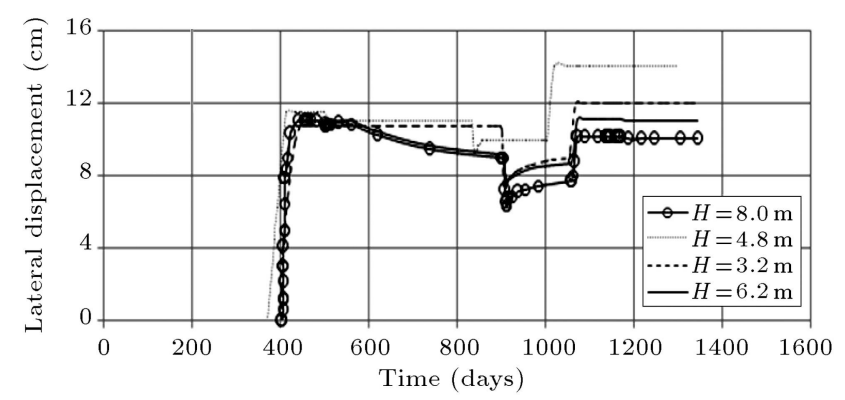

Figure 12. The maximum horizontal settlement of abutment for different depths of reinforcement.

horizontal displacements of the abutment, respectively, for different lengths of geogrid. As observed, the maximum vertical settlement of $60 \mathrm{~cm}$ was obtained after construction of abutment by using geogrids of $11 \mathrm{~m}$ long, which could be due to the occurrence of punching under the abutment caused by insufficient length of geogrid. However, the vertical settlement of the abutment is almost identical for the lengths of 17 , 21 , and $25 \mathrm{~m}$ and much lower than that for geogrids of $11 \mathrm{~m}$ long. According to Figure 9, the horizontal displacement for geogrids of $17 \mathrm{~m}$ long is approximately $5 \mathrm{~cm}$ higher than those for geogrids of 21 and $25 \mathrm{~m}$ long are. Therefore, the geogrid length of $21 \mathrm{~m}$ was selected for investigating the other properties of geogrid.

As mentioned earlier, the effect of the depth of reinforced soil on the vertical settlement and horizontal displacement of abutment was investigated by modelling the GRA using geogrids of $21 \mathrm{~m}$ with $500 \mathrm{kN} / \mathrm{m}$ normal stiffness. Figures 11 and 12 show the history of the maximum vertical settlement and the maximum horizontal displacement of the abutment, respectively, for different depths of reinforcement. As observed in Figures 11 and 12, the vertical settlement and lateral displacement of abutment decreased with increasing the depth of reinforcement. By increasing the depth of reinforcement from $3.2 \mathrm{~m}$ to $8 \mathrm{~m}$ (20 layers of geogrid), the vertical settlement decreased from $104 \mathrm{~cm}$ to $60 \mathrm{~cm}$ and the horizontal displacement decreased from 14 to $6 \mathrm{~cm}$.

In order to investigate the effect of the normal stiffness of geogrids on the displacements of abutment,

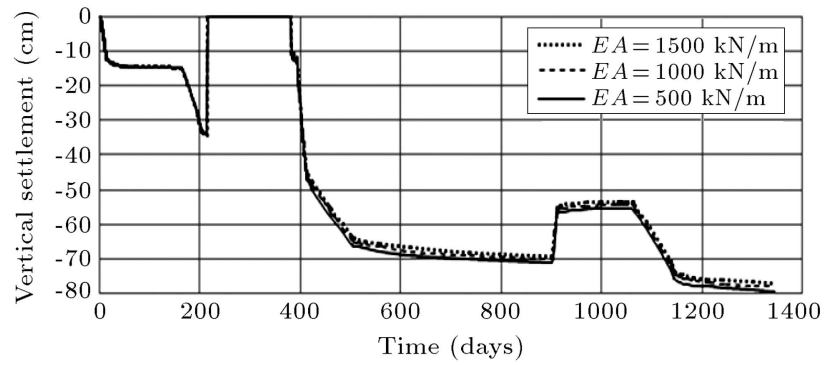

Figure 13. The maximum vertical settlement of the abutment on soil reinforced by geogrid with different normal stiffness values.

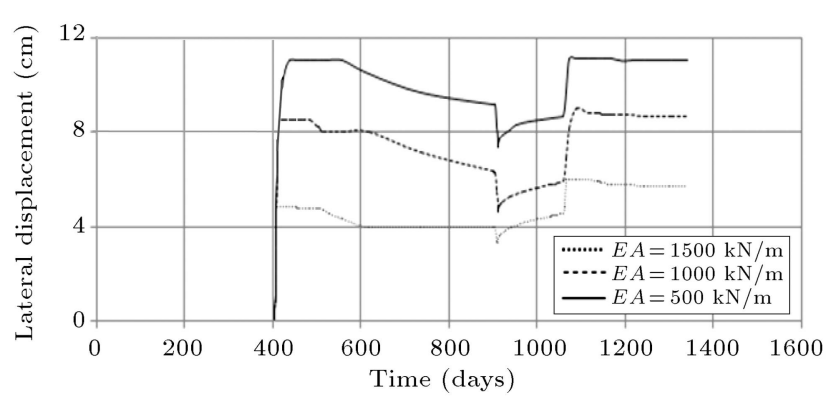

Figure 14. The maximum horizontal displacement of the abutment on soil reinforced by geogrid with different normal stiffness values.

geogrids with different normal stiffnesses of 500, 1000, and $1500 \mathrm{kN} / \mathrm{m}$ were used. For all cases, the depth of reinforced soil was $6.2 \mathrm{~m}$ and the length of the geogrids was $21 \mathrm{~m}$. Figure 13 shows the maximum settlement of the abutment for geogrids with different normal stiffness values. As is clear, the vertical settlement of abutment was not affected by the normal stiffness of geogrid. Figure 14 shows the maximum horizontal displacement of abutment head for different normal stiffness values of geogrid. As observed, the horizontal displacement of abutment decreased with increasing the normal stiffness of geogrid. The maximum horizontal displacement of $11 \mathrm{~cm}$ for the geogrid with the normal stiffness of $500 \mathrm{kN} / \mathrm{m}$ reduced to approximately $5 \mathrm{~cm}$ for the geogrid with the normal stiffness of $1500 \mathrm{kN} / \mathrm{m}$.

\subsection{Comparison of PA with GRA}

Figure 15 shows the vertical settlement of the abutment on piles (PA) and the abutment on geogrid reinforced soil (GRA). As can be seen, in equal conditions, the maximum vertical settlement of the $\mathrm{PA}$ is less than that of the GRA. The figure also shows that, after constructing the pile, the vertical settlement of the PA does not increase anymore.

Figure 16 shows the maximum horizontal displacement of PA and GRA with different stiffness values of geogrid. As can be seen, increasing the stiffness of the geogrid decreases the horizontal displacement. The horizontal displacement of the abutment decreases 


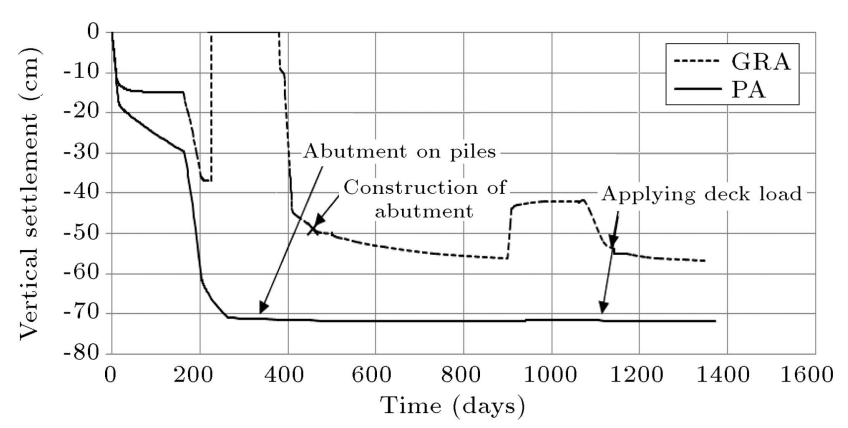

Figure 15. The maximum settlement of the abutment in PA and GRA.

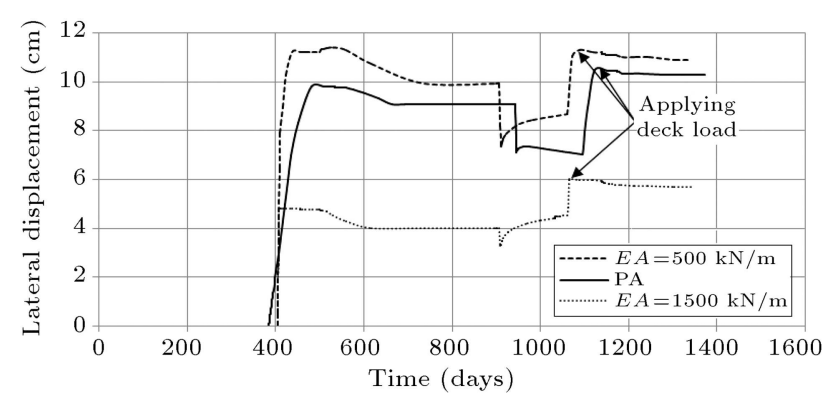

Figure 16. The maximum lateral displacement of the PA and GRA.

by $82 \%$, as the stiffness increases from $500 \mathrm{kN} / \mathrm{m}$ to $1500 \mathrm{kN} / \mathrm{m}$. In this figure, it can also be seen that the horizontal displacement of the abutment on soil reinforced by geogrids with the normal stiffness of $500 \mathrm{kN} / \mathrm{m}$ is higher than that of the PA. However, as the stiffness increases to $1500 \mathrm{kN} / \mathrm{m}$, the maximum horizontal displacement reduces to a value less than that of the PA.

\section{Conclusions}

This research investigated the performance of constructing bridge abutment on piles and geogrid reinforced soils in reducing the vertical and horizontal settlement of the abutments. The following are brief conclusions.

- Verification of the model showed that it could well predict the vertical settlement, occurring throughout the construction of the embankment, piles and abutment; however, the lateral displacement of the pile, after removing the upper part of the fill, cannot accurately predict the vertical displacement;

- Constructing the abutment on piles and geogrid reinforced soil could reduce both the horizontal and vertical displacements;

- The vertical settlement of the GRA was higher than that of PA, and is independent of the stiffness of the geogrid. However, the horizontal displacement of the GRA could be less than that of the abutment on pile, when the stiffer geogrid was used for reinforcement;

- The horizontal displacement and the vertical settlement of the abutment decreased with an increase in the length of geogrid layers;

- The horizontal and vertical displacements of the abutment decreased with an increase in the reinforcement depth;

- Since the vertical displacement of the bridge abutment is more important than the horizontal displacement for highway ride quality, it is suggested that piles be used for construction of the abutments on soft soils.

\section{References}

1. Randolph, M.F. "Science and empiricism in pile foundation design", Geotechnique, 53(10), pp. 847-875 (2003).

2. Zhang, W., Qin, B., Wang, B., and Ye, J. "Reduction of earth pressure and displacement of abutment with reinforcement filling", Geotechnical Eng. for Disaster Mitigation and Rehabilitation, 20, pp. 815-820 (2008).

3. Detert, O. and Alexiew, D. "Physical and numerical analyses of geogrid-reinforced soil system for bridge abutments", From Research to Design in Europe. Practice Conf. Bratislava, Slovak Republic (2010).

4. Hara , T., Yu , Y., and Ugai, K. "Behavior of piled bridge abutments on soft ground: A design method proposal based on 2D elasto-plastic-consolidation coupled FEM", Comput. and Geotech., 31, pp. 339-355 (2004).

5. Lee, K.Z.Z. and Wu, J.T.H. "A synthesis of case histories on GRS bridge-supporting structures with flexible facing", J. Int. Geotex. and Geomembr, 20, pp. 181-204 (2004).

6. Skinner, G.D. and Rowe, R.K. "Design and behavior of a geosynthetic reinforced retaining wall and bridge abutment on a yielding foundation", Geotex. and Geomembr., 23, pp. 234-260 (2005).

7. Ellis, E.A. and Springman, S.M. "Modelling of soilstructure interaction for piles bridge abutment in plane strain FEM analyses", Computs. and Geotech., 28, pp. 79-98 (2001).

8. Wang, H.T., Chen, Z.P., and Xiao, L.J. "Plane strain finite element analysis of a piled bridge abutment on soft ground", 1st Conf. Comput. Meth. in Eng. and Science, Tsinghua University Press and Springer, pp. 600-607 (2006).

9. Fahel, S., Palmeria, E.M., and Ortigao, J.A.R "Behaviour of geogrid reinforced abutments on soft soil in the BR 101-SC highway, Brazil", Conf. on Advances in Transport. and Geoenviron. Sys. Using Geosynthetics, ASCE, pp. 257-270 (2000). 
10. Zheng, Y. and Fox, P. "Numerical investigation of geosynthetic-reinforced soil bridge abutments under static loading", J. of Geotec. and Geoen. Eng., 40, pp. 1-13 (2016).

\section{Biographies}

Hasan Taherkhani received his $\mathrm{PhD}$ degree in the field of Pavement Engineering from University of Nottingham in 2006. Since he has worked at the University of Zanjan. Then, His main activities include teaching undergraduate and graduate courses, advising master and $\mathrm{PhD}$ students, and administration works. His research interest is working on pavement materials, pavement analysis and design. Until now, he has published more than 45 papers in national and international journals and presented more than 100 papers in national and international conferences. He has also authored two books in the field of pavement analysis.

Milad Tajdini is a PhD student of Civil Engineering at Tabriz University. $\mathrm{He}$ is a member of National Elite Students Foundation. He received BS degree from Sharif University of Technology. Currently, he is studying Geotechnics at Tabriz University where he is ranked the best among all his peers. His publications during his $\mathrm{PhD}$ program include two books focused on soil dynamics, one of which approaches the subject from an Earthquake Engineering perspective and the other from a Geotechnical one. His research interests are mainly located in the area of soil improvement and, recently, using nanotechnology in this path.

Abdolreza Rezaee Arjroodi is an Associated Researcher in Road, Housing, and Urban Development Research Centre as part of Transportation Engineering. He was the Economy Manager of Transportation of BHRC for years. He obtained MSc of Road Engineering in Islamic Azad University of Central Tehran Branch.

Hosein Zartaj is a PhD student in Civil Engineering at Tabriz University. His researches focus on soil improvement and interaction between soil and foundations. He is a technical expert of KNAUF Company in the Middle East and trains experts from Turkey, Iran, and Afghanistan. 